\title{
A cultura surda a partir da linguagem dos quadrinhos
}

\author{
The deaf culture from the comics language \\ La cultura sorda a partir del lenguaje de los cómics
}

\author{
Karina do Nascimento Sousa Lima ${ }^{1}$ \\ Nádia da Cruz Senna
}

\begin{abstract}
Resumo
A proposta deste texto é explorar o cruzamento de experiências visuais surdas e ouvintes a partir de produções de HQs e analisar os recursos utilizados por estes dois trabalhos a fim de produzir sentido. O trabalho terá como referencial de análise a obra de Will Eisner e Scott McCloud e tudo isso será permeado também a partir de uma sustentação acerca de uma cultura surda que é retratada nas histórias de quadrinistas surdos, buscando entender que tipo de discussão tais artistas propõem e qual a importância de se discutir isso hoje em dia. O trabalho permeia tanto a linguagem visual da produção do quadrinho, quanto uma linguagem antropológica/social, buscando apresentar de forma sucinta o que é o sujeito surdo, cultura surda e procurar desmistificar alguns mitos criados a respeito desses sujeitos, trazendo olhares de artistas que são surdos.
\end{abstract}

Palavras-chave: Cultura surda; quadrinhos; experiência visual; surdo

\section{Resumen}

La propuesta de este texto es explorar el cruce de experiencias visuales sordas y oyentes a partir de producciones de HQ y analizar los recursos utilizados por estos dos trabajos para producir sentido. El trabajo tendrá como referencia de análisis la obra de Will Eisner y Scott McCloud y todo ello se impregna también a partir de una sustentación acerca de una cultura sorda que se retrata en las tiras de Matt Daigle, buscando entender qué tipo de discusión el artista propone y que, ¿cuál es la importancia de discutirlo hoy en día. El trabajo permea tanto el lenguaje visual de la producción del cómico, como un lenguaje antropológico / social, buscando presentar de forma sucinta lo que es el sujeto sordo, cultura sorda y procurar desmitificar algunos mitos creados respecto a esos sujetos, trayendo las miradas de artistas que san sordos.

Palabras-clave: Cultura sorda; cómics; experiencia visual; sordo

\begin{abstract}
The purpose of this text is to explore the crossing of deaf visual experiences and listeners from comic book productions and to analyze the resources used by these two works in order to make sense. The work will be based on the work of Will Eisner and Scott McCloud and all this will be permeated also from a support of a deaf culture that is portrayed in the stories of deaf comic artists, trying to understand what kind of discussion these artists propose and what is the importance of discussing this nowadays. The work permeates both the visual language of the production of the comic and an anthropological / social language, trying to present succinctly what is the deaf subject, deaf culture and seek to demystify some created myths about these subjects, bringing the look of deaf artists.
\end{abstract}

Keywords: Deaf culture; comic books; visual experience; deaf

\footnotetext{
${ }^{1}$ Graduanda em Artes Visuais Bacharelado CA-UFPEL; Universidade Federal de Pelotas; Bolsista pela Prec; Desenho da Figura Humana; Pelotas, Rio Grande do Sul, Brasil; ka.nslima @ gmail.com

${ }^{2}$ Doutora em Ciências da Comunicação pela prpg-USP; Professora da Universidade Federal de Pelotas; Pelotas, Rio Grande do Sul; alecrins@uol.com.br
} 


\section{Introdução}

Antes de tratar das obras dos artistas surdos, farei um breve panorama do que são os quadrinhos, relacionarei a experiência visual desta linguagem a experiência visual dos surdos, apresentarei também, brevemente a cultura surda para, aí sim, trazer algumas obras destes artistas e analisá-las.

Os quadrinhos são um tipo de gênero narrativo que mescla imagem com texto a fim de produzir sentido. Segundo Scott McCloud, os quadrinhos são: "imagens pictóricas e outras justapostas em sequência deliberada destinadas a transmitir informações e/ou a produzir uma resposta no espectador." (MCCLOUD, 1995 p. 9.). Suas manifestações podem ser encontradas em vários períodos ao longo da história e produzidos pelos mais diferentes povos. Os primeiros registros conhecidos são das pinturas egípcias em que se retratavam o cotidiano dos escravos no cultivo sob a supervisão de um superior, essas pinturas possuíam uma sequência narrativa que podia ser lida de baixo para cima. Mais pra frente já no século XVIII o artista William Hogarth produziu uma série de pinturas denominada "O progresso de uma prostituta", que fora idealizada para ser disposta em sequência justaposta, assemelhando-se a tiras quadrinizadas. Não existem registros que marcam exatamente o início da linguagem sequencial dos quadrinhos, no entanto o pai desse estilo narrativo é Rodolphe Töpffer que já em meados do século XIX retratava de forma satírica e caricatural personagens e situações da sociedade em que vivia. Este autor foi o primeiro artista que mesclou em uma mesma obra imagem e texto a fim de se atingir uma completude de sentido. A partir dele, que foi um grande marco na história dos quadrinhos, foi que esse estilo passou a se aperfeiçoar em termos de refinamento estético, de roteiro e de disposição.

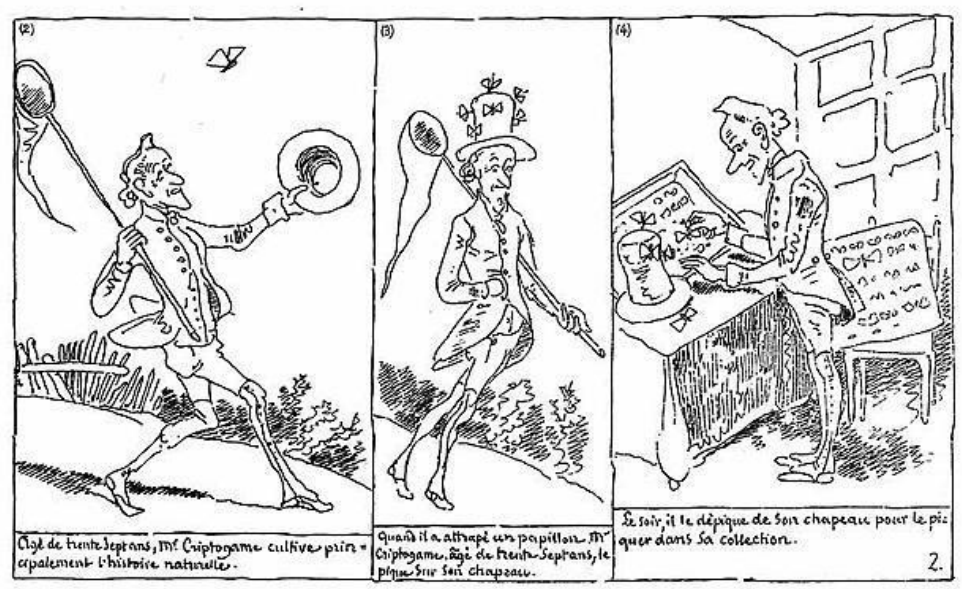

Figura 1 - Rodolphe Topffer, acessado 10/01/2019 
Várias foram as técnicas utilizadas pelos mais diversos artistas para construir sua narrativa, xilogravuras, colagens, pinturas etc. Tais narrativas podem ou não serem organizadas em quadros perfeitamente delimitados (como é o caso do mangá, por exemplo). O fato é que, o que faz com que tal quadrinho produza sentido é a experiência visual que ele propõe a partir de elementos como: balões de fala, onomatopeias, caligrafia, expressão facial dos personagens, disposição dos quadros na folha e ainda, a condução do olhar do espectador em uma linearidade. Temos que ter em mente que essas experiência visual citada é produzida por um ouvinte destinada, na maioria das vezes, a outro ouvinte. Vamos observar mais para frente que determinados elementos não aparecem em uma narrativa surda.

\section{Cultura Surda}

Antes de apresentar o trabalho de um artista surdo, devo contextualizar o meio ao qual ele se insere. Surdo, segundo Lebedeff é "aquela pessoa que, 'por ter perda auditiva, compreende o mundo por meio de experiências visuais, manifestando sua cultura principalmente pela Língua Brasileira de Sinais - Libras"”. (LEBEDEFF, 2016, p.10.) Dessa forma, a Surdez para além de ser uma condição física é um modo de ser e existir no mundo.

O lugar social do sujeito surdo pode ser analisado a partir de diversas lentes, a depender do contexto histórico e classe social. Na Antiguidade Clássica, por exemplo, apesar de sujeitos ditos "anormais" serem acolhidos pelas leis hebraicas, ainda se praticavam sacrifícios e abandonos em relação a eles, por serem considerados castigos divinos, bem como "inúteis" à vida pública, indomesticáveis e selvagens.

Vinculada a uma concepção aristotélica cuja oralidade é imperativo para participação política ativa em sociedade, a Antiguidade vincula o "animal político" à habilidade do homem de falar e construir linguagem, atribuindo a ele sua verdadeira vocação política. Dessa forma, essa concepção quase tratada como um dogma colaborou para subjugar a capacidade de sociabilidade e cognitiva do sujeito surdo, criando uma série de aspectos estigmatizados a respeito desses indivíduos que perduram até a atualidade. No entanto, segundo Eiji, alguns surdos (homens) de classe social mais privilegiada chegavam a ter alguma participação política de forma bem limitada, devido a inacessibilidade a língua oral, como afirma o autor:

Na Roma Antiga, por exemplo, a primazia da língua oral no dia-a-dia da vida pública (nos espaços de participação política, nos comícios e festejos, nas transações de vários tipos etc.), bem como a importância da oratória na formação de um cidadão, levam a crer que à grande parte dos surdos restava um pequeníssimo espaço de atuação." (EIJI, Hugo - culturasurda.net/ - Acessado 11/01/2019 âs 17:05) 
Aqueles que, no entanto, não possuíssem bens eram excluídos de atividades das mais simples da vida pública, comícios, colheitas, comércio etc.. Devido a sua impossibilidade de socialização com o outro.

A partir da Idade Média, com a ascensão da igreja católica e o anseio pela evangelização do povo a fim de conseguir fiéis, a igreja passa a acolher o povo surdo, até então marginalizado pela sociedade, de forma caritativa. Com o passar dos anos, já no período Renascentista que carrega consigo uma série de transformações sociais, científicas, religiosas e educacionais, esse período passa a depositar um novo olhar sobre a surdez e o sujeito surdo. Essa mudança se inicia pelos esforços do monge beneditino Pedro Ponce de León, considerado até hoje o primeiro educador de surdos.

Advindo de uma cultura religiosa, cujo silêncio era sinônimo de devoção e desvencilhamento da vida mundana para uma maior aproximação com Deus, dentro da comunidade monástica foram desenvolvidos alguns gestos com os quais os monastas poderiam interagir entre si sem quebrar o voto de silêncio. Para que essa tradição da gestualidade se mantesse, os monges desenvolveram uma espécie de dicionário ${ }^{3}$ que era partilhado de geração em geração, bem como com outros monastérios. Ponce de León, no entanto passou a partilhar desse conhecimento com alguns surdos da classe nobre, ensinando-os a ler e a escrever. Esse feito foi determinante para que o cientista Girolamo Cardano desmistificasse a teoria de que o surdo não possuía racionalidade, segundo ele "estar privado do universo sonoro não implicava estar impedido de aceder à linguagem, ao pensamento lógico e ao raciocínio." (EIJI, 11/01/2019). Não apenas essas duas figuras como muitos outros teóricos foram fundamentais para as mudanças de concepção acerca da surdez, como mostra EIJI:

O que se destacam dessas iniciativas, como as de Pedro Ponce de León, de Joaquim Pascha - que no século XVI também "treinou dois de seus próprios filhos surdos" (BERTHIER, 1984 apud NASCIMENTO, 2006, p. 257) -, de Ramirez de Carrión (educador espanhol), de Girolamo Cardano, de Juan Pablo Bonet, entre as de outros protagonistas conhecidos (e desconhecidos) dos séculos XVI e XVII, são as novas concepções que firmaram sobre a surdez e sobre o ensino/aprendizado de indivíduos surdos - concepções que em grande medida contribuíram para que fossem revistas as crenças da não-educabilidade irremediável e da condição não-humana desse grupo. (EIJI, Hugo - culturasurda.net/ - Acessado 11/01/2019 âs 17:05)

Anos mais tarde, já no século XVIII dois educadores ganham popularidade por fundarem duas metodologias de ensino de surdos: O Oralismo e a Gestualidade (posteriormente chamado sinalização).

\footnotetext{
${ }^{3}$ Monasteriales Indicia, que possuía 127 sinais descritos.
} 
Samuel Heinicke ${ }^{4}$ foi o responsável por fundar o método do oralismo, cujo objetivo é ensinar aos surdos a falar. Segundo ele, apenas a partir da fala seria possível chegar ao letramento, para isso ele prezava por uma 'ortopedia da fala' ensinando a como pronunciar os fonemas. Para ele era inadmissível o uso de qualquer tipo de gesticulação para se comunicar. Esse período, na Europa, era o de uma tentativa de unificação do ensino, nesse sentido, o padrão que Heinicke partia era o de ensino ouvinte, procurando adequar o surdo a um padrão de ensino específico. Em contrapartida, em Paris, o educador CharlesMichel de l'Épée utilizou como metodologia basilar o que ele chamou de "sinais metódicos", um sistema gestual que ele construía a partir de um repertório dos próprios alunos que ingressavam em sua instituição. Os gestos eram criados a partir de um léxico gestual dos próprios surdos de suas realidades individuais, juntamente com a criação do próprio educador, procurando também, se adequar à gramática da língua francesa para facilitar a alfabetização desses sujeitos e o acesso a outras disciplinas presentes nas escolas ouvintes. Sua ânsia pela difusão de sua metodologia, fez com que ela se propagasse por todo o estado chegando a fundar o primeiro Instituto Nacional de Surdos-Mudos ${ }^{5}$ de Paris.

Com a democratização do acesso do surdo à educação, esses indivíduos passaram a ter um lugar dentro da sociedade, assumindo profissões antes impensáveis a eles. Se antes eles eram educados por ouvintes, a partir da formação numerosa de surdos nessas instituições, eles próprios começaram a educar outros surdos e os auxiliarem a alcançar outros espaços e profissões no meio social:

\begin{abstract}
Em meados do séc. XIX havia mais de cento e cinquenta escolas na Europa e vinte e seis nos Estados Unidos que usavam a língua gestual. A educação de surdos estava em seu período de ouro. Os surdos tinham acesso à educação por meio da sua língua materna. Na Europa e na América cada vez mais alunos surdos completavam a educação básica. Foram lançados então os cursos secundários para surdos em Hartfort, Nova Iorque e Paris. Os alunos surdos tiveram pela primeira vez a possibilidade de continuarem os seus estudos, tornando-se muito deles professores de surdos. Em meados do século dezanove metade dos professores nas escolas americanas e francesas eram surdos (hoje são uma raridade). (EIJI, Hugo - culturasurda.net/ Acessado 13/01/2019 âs 11:24)
\end{abstract}

A partir de então, cria-se uma rede de compartilhamento de conhecimentos por parte de indivíduos de mesma língua materna. Nesse período podemos demarcar, talvez, o início do que chamamos de comunidade surda que passam a compartilhar elemento culturais entre eles e ajudando a difundir tais conhecimentos mundo afora.

No entanto, no século XIX no ano de 1880 tudo mudou devido ao Congresso de Milão, evento que discutiu durante sete dias que rumos tomariam a educação de surdos. Tendo, como dito acima, duas metodologias bastante difundidas no mundo (Oralismo e Sistema Gestual), foi

\footnotetext{
${ }^{4}$ Educador alemão, aplicou sua metodologia na cidade de Leipzig. Considerado "pai do método alemão";

${ }^{5} \mathrm{O}$ termo 'surdo-mudo' atualmente não é mais utilizado, devido o reconhecimento da capacidade do surdo aprender a falar (se for vontade do mesmo). Nesse sentido, chamamos esses indivíduos apenas de Surdo.
} 
discutido qual seria o método mais adequado para seguir educando os surdos, não apenas na Itália como no mundo. Composta por uma bancada majoritariamente ouvinte, determinou-se então como mais adequado o Oralismo. Tendo dito isso, qualquer manifestação gestual passou a ser proibida tanto em instituições de ensino como também em locais públicos. Os gestos passaram a ser considerados como manifestações de ordem primitiva e limitada. A surdez voltou então a ser tratada enquanto uma patologia com necessidade de ser curada, o surdo foi obrigado a aprender a oralizar, os professores surdos foram afastados de seus cargos e a língua gestual passou a ser marginalizada.

Ao mesmo tempo, muitos surdos procuravam resistir clandestinamente e foi a partir dessa resistência em consolidar a Língua Gestual (hoje de Sinais) como língua materna do surdo e responsável por outras formas de práticas culturais que, no Brasil por exemplo, hoje se tem decretado por Lei a obrigatoriedade de se existirem escolas próprias para alunos surdos, bem como o ensino de LIBRAS nas escolas regulares.

Toda essa mobilização surda a fim de manter, fortalecer e propagar o ensino de sua língua materna para outros tantos surdos ao longo do mundo renderam frutos que foram colhidos em outras áreas que não apenas a educação. Tendo como marco cultural sua língua cuja manifestação se dá utilizando todo o corpo (principalmente as mãos), os surdos passaram a explorar as potencialidades do corpo em outras áreas. Muito se engana aquele que acha que surdo não tem acesso a cultura, ele não apenas tem como também a produz. Tatiana Lebedeff em seu artigo realiza um maravilhoso apanhado de uma série de grupos e artistas que produzem dentro de diversos campos de atuação desde o esporte até os quadrinhos.

Nesse sentido, o surdo faz parte de um grupo social que possui uma cultura própria, língua própria e consequentemente manifestações culturais próprias, que se dão predominante através de estímulos visuais. Sendo assim, entendemos que "cultura surda é o jeito de o surdo entender o mundo e de modificá-lo" (2016, p.11), através de sua língua própria que é a Libras (no caso do Brasil), que além de servir como possibilidade de tradução da língua portuguesa que permite o acesso a obras que antes os surdos não possuíam, permite a produção de cultura dos mais diversos meios explorando a principal ferramenta do surdo que é seu próprio corpo. Exemplo disso são as coreografias surdas, cujo tempo é marcado também por estímulos visuais ou táteis, como lâmpadas que acendem e apagam em um ritmo ou vibrações no chão. Já no caso dos quadrinhos, que é o que mostrarei a seguir, os artistas buscam tratar do seu cotidiano enquanto surdo participante de uma sociedade que não entende sua língua e tampouco conhece sua cultura, ou então determinados artistas refazem histórias famosas da cultura ouvinte e apresentam como protagonista o sujeito surdo, de modo a subverter determinados estereótipos 
construídos a respeito do surdo, tais como: incapacidade, inteligência inferior, dependência e pessoa atrapalhada.

\section{O surdo nos quadrinhos}

\subsection{Matt Daigle}

Para dar início a apresentação dos quadrinistas surdos, trago então o artista Matt Daigle. Artista norte-americano natural do Texas, Daigle retrata em suas tiras cenas cotidianas suas e com sua família, onde ele trata de forma cômica, situações que ele enfrenta com os ouvintes que não tem conhecimento da língua de sinais, nem da cultura permeada pela mesma. Suas tiras trabalham de forma cômica situações de cunho particular do sujeito surdo e também situações reconhecíveis por pessoas que convivem com tais sujeitos.

Elementos que são extremamente comuns em suas tiras são linhas que indicam movimento. Mesmo apresentando texto, esse recurso é utilizado apenas como artificio de tradução do movimento proposto pelo desenho. Em outros momentos em que aparecem a esposa e o filho, são colocados balões de fala, já quando se trata dele próprio as linhas do movimento são evidenciadas e um balão é colocado apontando para o movimento. Dificilmente são colocados onomatopeias nas tiras, elas estão presentes em algumas, no entanto elas só são colocadas quando o autor coloca a esposa (ouvinte) está presente na narrativa.

Se realizarmos uma comparação de uma tira ouvinte com a tira surda verificamos diferenças de abordagem, trago então dois exemplos:
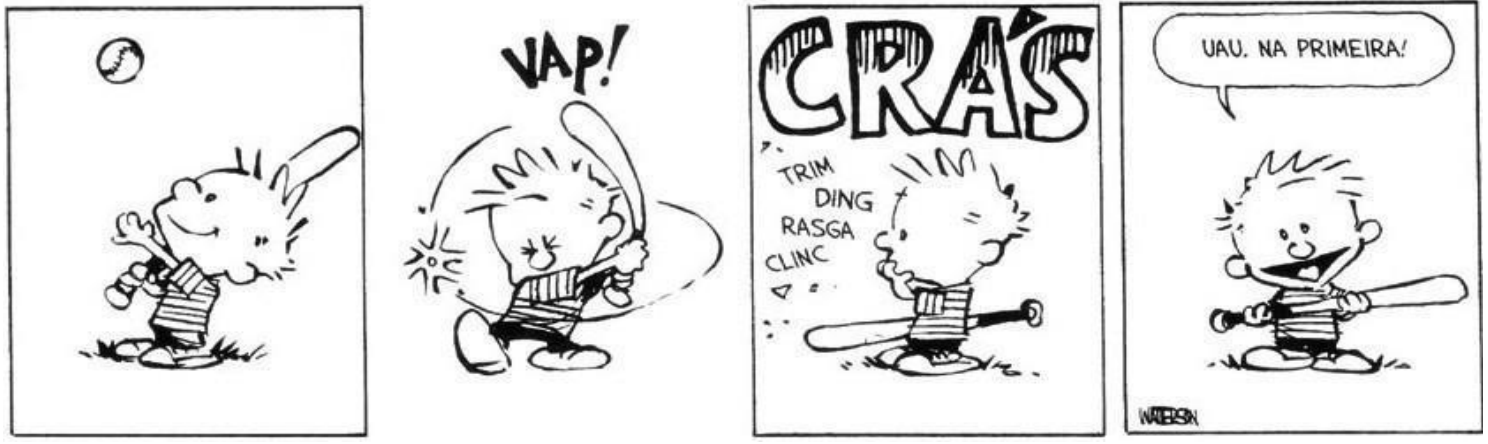

Figura 2 - Calvin e Haroldo - E foi assim que tudo começou 

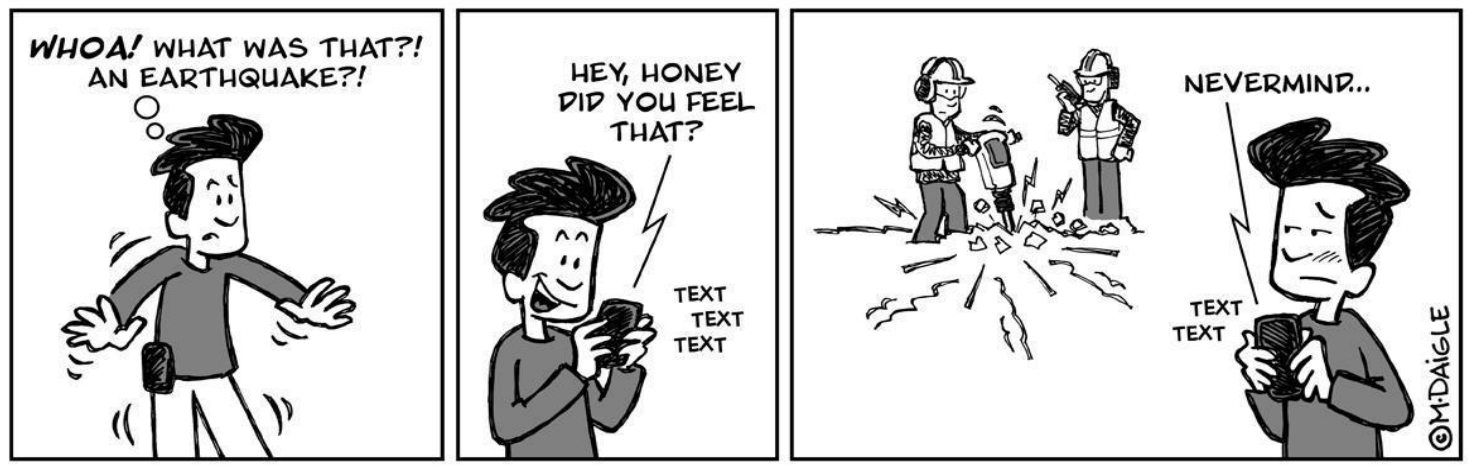

Figura 3 - That Deaf Guy - 20/04/2010

No caso da tira de Calvin, as linhas servem como indicação de um movimento mecânico a fim de gerar outra coisa (no caso o lançamento da bola em uma direção). O recurso de fala é uma balão e a onomatopeia é o ponto alto para o entendimento da graça da tira, se fosse retirado esse recurso talvez o sentido não se completasse. Já no caso da tira de Matt tudo se resolve visualmente, mesmo que existam textos narrando os pensamentos do personagem, se retirassem os recursos textuais ainda sim entenderíamos a tira (claro, se a pessoa que a lesse tivesse conhecimento que o personagem principal é surdo).

Em praticamente todas as tirinhas produzidas, o autor se apresenta como protagonista, juntamente com sua esposa e filho (ambos ouvintes) em um contexto de desinformação por parte dos pessoas que os rodeiam, enfrentando situações que beiram o ridículo. Por esse motivo também, ao longo de outras tiras ele faz uma espécie de tutorial (que pode ser acessado em seu site) em que ele diz o que deve e o que não deve ser feito na presença de um surdo.

Daigle também é responsável por desenvolver um outro projeto denominado Deaf Reel - A Deaf Parody Movies, em que ele sintetiza determinadas situações vivenciadas por surdos a partir do retrato de filmes conhecidos pela cultura pop ouvinte. Então ele retrata grandes superheróis como aquele que salva o surdo da oralização, o personagens surdos que usam aparelhos auditivos, satirizando e questionando a ausência de protagonismo surdo nas grandes telas e procurando quebrar o imperativo que prega: "se não fala, não comunica". 

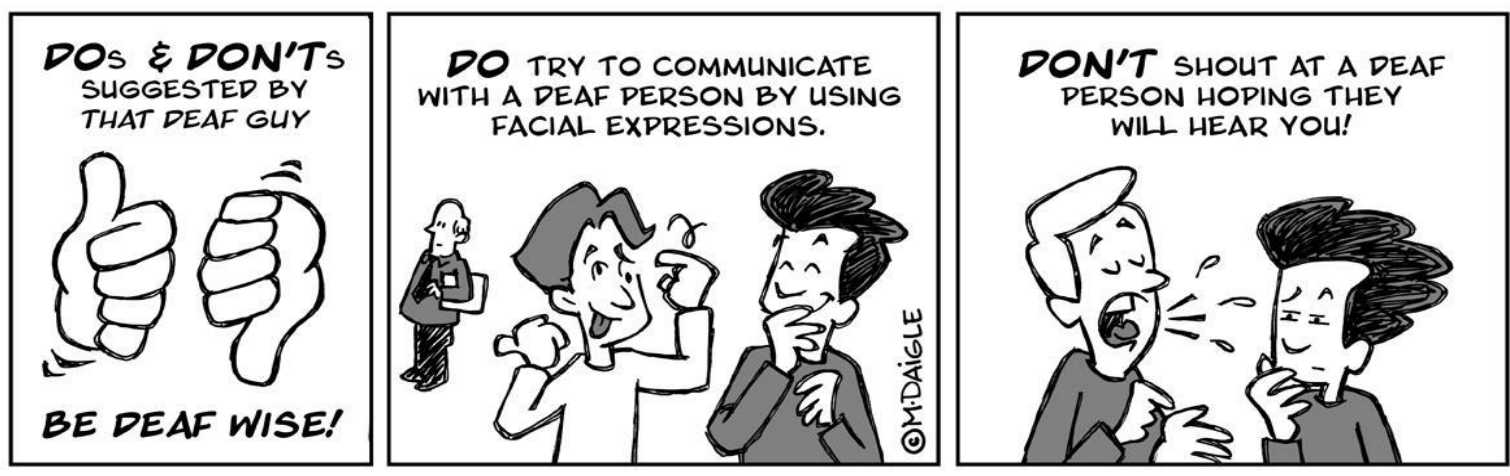

Figura 4 - That Deaf Guy - 06/04/2010

\subsection{Adrean Clark}

Adrean Clark além de cartunista e surda, é também autora de uma série de livros em que ela aborda a língua escrita de sinais (SignWriting - ASL - nos Estados Unidos). Natural da Carolina do Norte, foi aluna de uma escola para surdos do estado e também é licenciada pela Gallaudet University (Universidade para alunos surdos). Como cartunista, a artista se dedica a produzir tiras em que ela trata de sua vida cotidiana e no trabalho como pessoa surda. $\mathrm{O}$ diferencial de suas tirinhas é a mescla de elementos visuais que a artista utiliza. Além de utilizar o texto em língua inglesa (natural em qualquer tira ou quadrinho, independente de ser surdo ou ouvinte), ela escreve juntamente a SignWriting, que divide igualmente o espaço da tira com a escrita tradicional.

Como foi dito anteriormente, Clark é autora de livros abordando a grafia específica da Língua de Sinais Americana. Em suas tiras, a artista se coloca como protagonista das narrativas, dessa forma o uso do SignWriting possui duas funções específicas em seu trabalho: a primeira é de servir como meio de expressar visualmente os sinais executados pela personagem na situação retratada e a segunda - e mais recorrente - é o de traduzir o texto em língua inglesa para a SignWriting, aumentando seu reconhecimento tanto pela comunidade ouvinte quanto pela comunidade surda. 


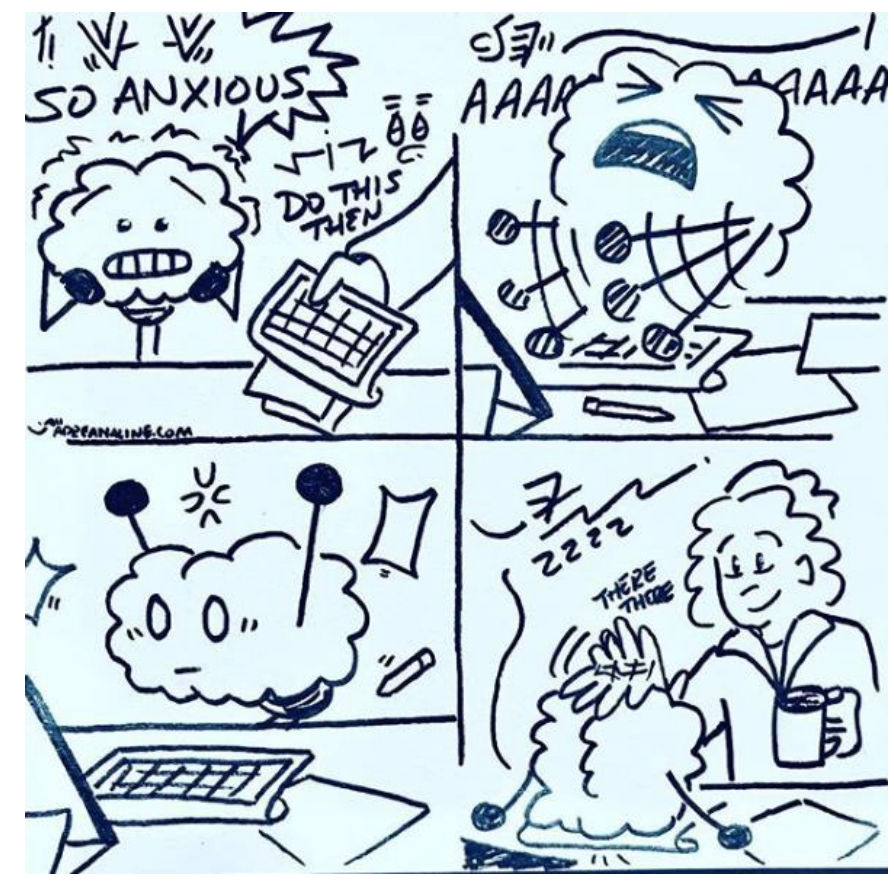

Figura 5 - Adrean Clark, disponível no instagram da artista

Adrean Clark é uma defensora da grafia SignWriting tendo, inclusive um site específico em que a artista ensina essa caligrafia ao leitor e mostra passo a passo de onde vêm os símbolos dessa escrita ${ }^{6}$. O uso desse recurso em uma tira quadrinizada é de uma imensa riqueza, tendo em vista que os símbolos próprios a escrita surda e aproximam muito com as linhas de indicação de movimento e expressividade dos quadrinhos.

O princípio da SignWriting é representar as mãos e seu respectivos movimentos. Para isso são utilizados setas, pontos e traços tudo de maneira bem simplificada. Para essa escrita não existe necessariamente alfabeto (apesar de a artista ter desenvolvido um), pois essa escrita é a grafia da língua de sinais que não se desenvolve a partir de soletração (datilologia), mas sim a partir de sinais específicos para palavras específicas. Dessa forma, o que essa escrita faz é

\footnotetext{
${ }^{6}$ Disponível em: http://www.aslwrite.com/
} 
representar em forma de símbolos o sinal de cada palavra na sintaxe específica do país de origem.

\section{Figura 6}
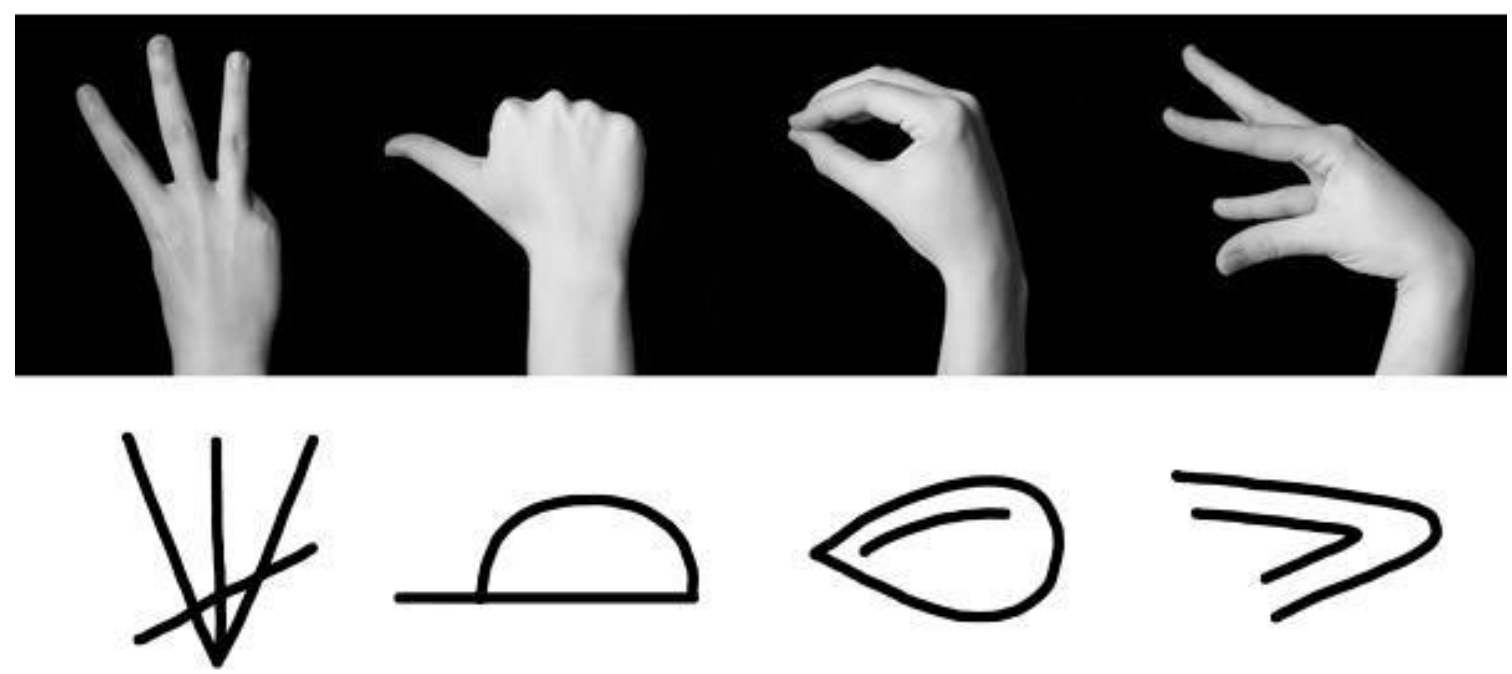

$$
\begin{aligned}
& \text { " }
\end{aligned}
$$

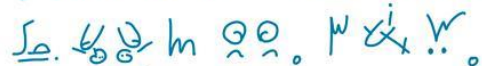

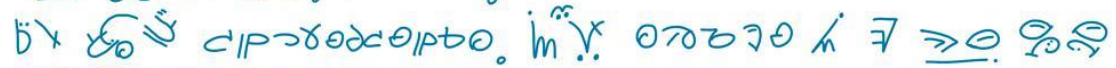

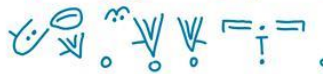

$$
\begin{aligned}
& \text { W }
\end{aligned}
$$

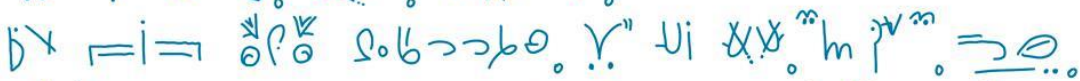

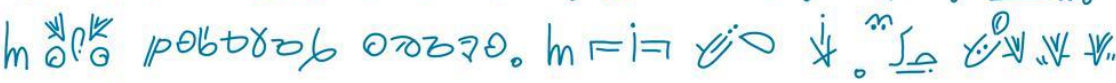

$$
\begin{aligned}
& \ln Q_{n} \gamma_{0} \\
& \partial x_{0} \quad \text { … }
\end{aligned}
$$

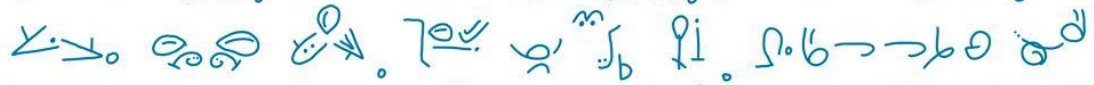

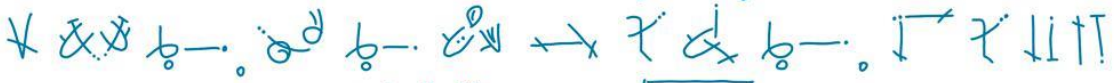

$$
\begin{aligned}
& \text { \% } \\
& \text { “V W }
\end{aligned}
$$

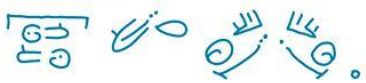

Figura 7 - Exemplo de texto em SignWriting

Will Eisner em seu livro aborda uma narrativa gráfica que se deriva de caligrafias de antigos povos e diz: 
Por meio do manejo habilidoso dessa estrutura aparentemente amorfa e de uma compreensão da anatomia da expressão, o desenhista pode começar a empreender a exposição de histórias que envolvem significados mais profundos e tratam das complexidades da experiência humana. (EISNER, 1985 p. 16.)

\subsection{Koe no Katachi}

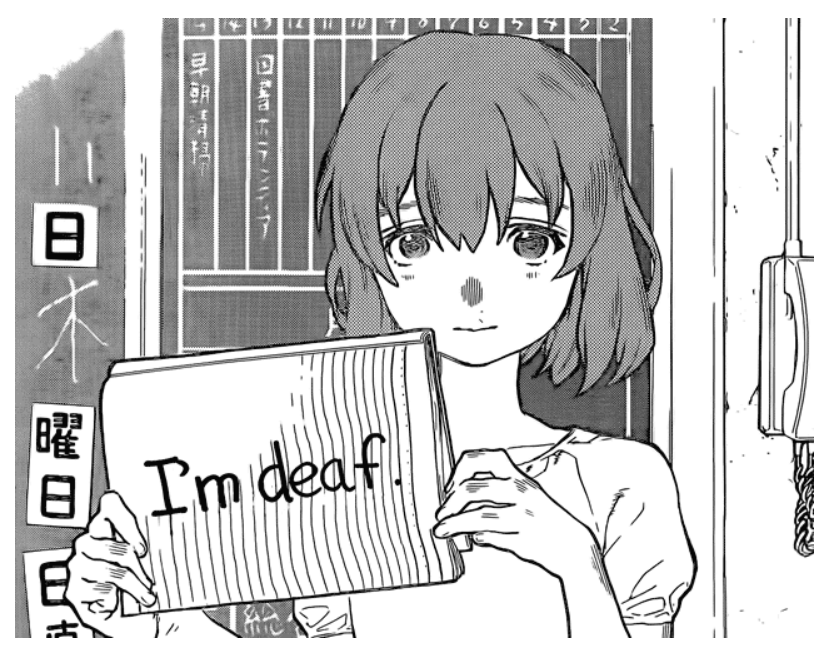

Figura 8

Por fim, apresento uma narrativa japonesa que ganhou repercussão mundial. Koe no Katachi (A Voz do Silêncio, no Brasil) é uma história produzida pela artista Yoshitoki Oima que, apesar de não ser surda, produziu uma belíssima história tratando de um conflito cultural muito específico. Tendo uma cultura tradicional muito rígida e baseada em padronização social, o Japão é conhecido por rejeitar o diferente e é basicamente do que a história trata.

Tendo como centro da narrativa a personagem Shouko que é surda e Ishida que é ouvinte, a história aborda a dificuldade de Shouko em se adaptar a vida escolar devido recepção negativa dos colegas, em especial Ishida, que pratica bullying com ela. Shouko é uma menina que apesar de surda, consegue pronunciar algumas palavras devido o uso de seu aparelho auditivo no entanto, devido a dificuldade que ela percebe de os outros compreenderem sua fala, ela ou se comunica através de seu caderno (escrevendo o que quer dizer) ou através da Língua de Sinais.

Ao longo da narrativa, é interessante perceber as soluções visuais que a artista encontra para representar os gestos das mãos dos personagens quando se executam algum sinal e os tipos de pontuação utilizados para enfatizar o silêncio da personagem. De forma crua a artista retrata de maneira crua a dificuldade de se viver em uma sociedade onde as diferenças são sinônimo 
de fraqueza e aberração. Colocando como condutor da narrativa um personagem ouvinte, a artista sensibiliza o leitor na medida em que ele, antes agressor, opressor, se torna também oprimido e procura se redimir com sua antiga vítima, não como um ato apenas de culpa e pena, mas como uma tomada de consciência de sua humanidade.

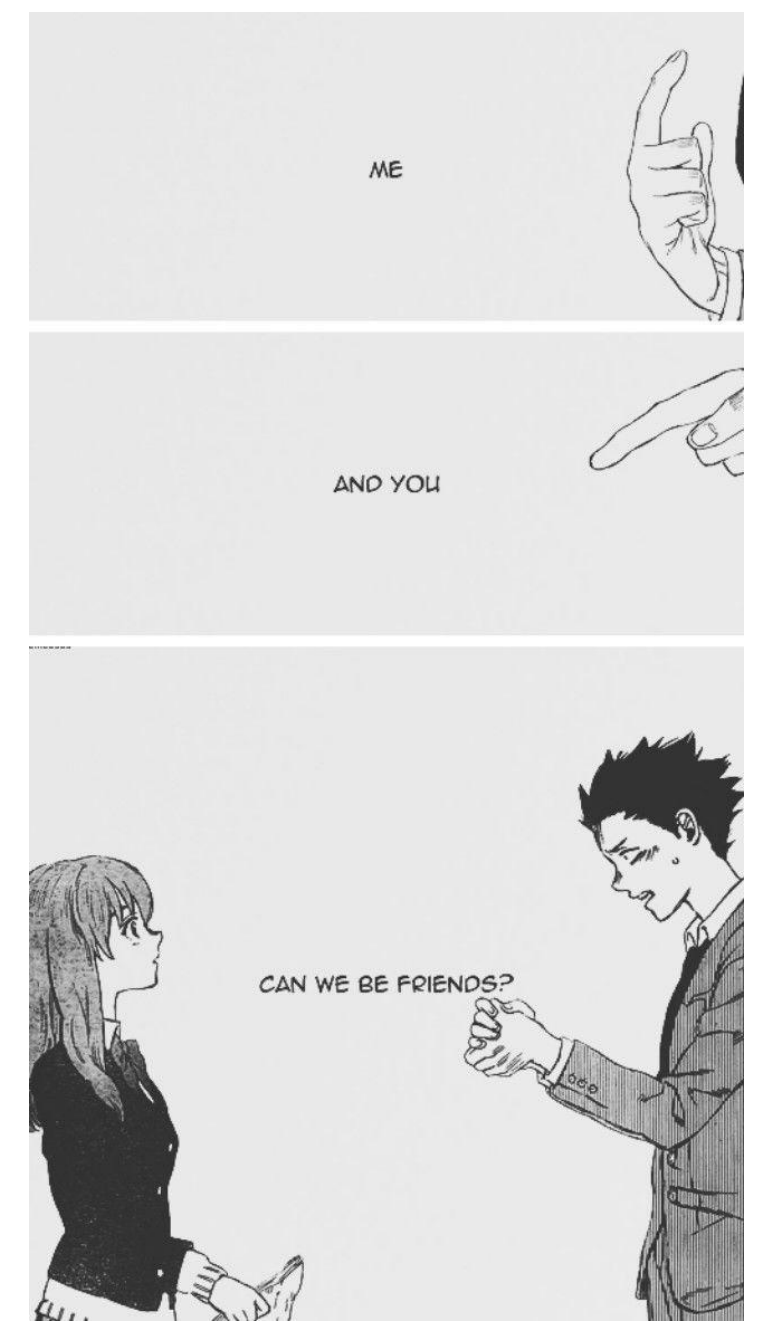

Figura 9

Conhecer e entender as produções culturais dos sujeitos surdos é de extrema importância para evitar que estereótipos que minimizam a imagem destes indivíduos sejam perpetuados. A valorização dessa e de outras formas de manifestações ajuda a manter essa ponte que liga a nossa cultura (ouvinte) à cultura surda forte e gerando conscientização e minimizando preconceitos existentes envolvendo o lugar do surdo na sociedade. 


\section{Referências}

LEBEDEFF, T.B. Língua de sinais e cultura surda: qual seu lugar na escola?. In: AQUINO, I. C.; CRESTAN, L. M.; DIAS, L. F. F.; DIEDRICH, M. S. Lingua, literatura, cultura e identidade - entrelaçando conceitos. Passo Fundo: UPF Universidade de Passo Fundo, 2016. Cap.1, p.9-22.

MCCLOUD, Scott. Desvendando os quadrinhos. São Paulo: Makron Books, 1995.

EISNER, Will. Quadrinhos e Arte sequencial. São Paulo: Martins Fontes, 1985.

http://www.adreanaline.com/?p=94

https://www.instagram.com/adreanaline/

http://blog.mdaigletoons.com/?cat=4 (acessado em 10/01/2019 ás 15:11)

http://www.thatdeafguy.com/?p=120 (acessado em 03/10/2017 ás 12:11)

http://tiras-do-calvin.tumblr.com/post/23128023665/calvin-e-haroldo-e-foi-assim-que-tudocome\%C3\%A7ou (acessado em 03/10/2017 ás 12:12)

https://culturasurda.net/ilustracoes-cartoons/ (acessado em 10/01/2019 ás 15:09)

https://culturasurda.net/antiguidade/

https://culturasurda.net/idade-media-moderna/

https://culturasurda.net/congresso-de-milao/

http://www.aslwrite.com/ 